\title{
Kinetic Resolution of Aromatic $\beta$-Amino Acids Using a Combination of Phenylalanine Ammonia Lyase and Aminomutase Biocatalysts
}

\author{
Nicholas J. Weise, ${ }^{a}$ Syed T. Ahmed, ${ }^{a}$ Fabio Parmeggiani ${ }^{a}$ and Nicholas J. Turnera* \\ a Manchester Institute of Biotechnology \& School of Chemistry, Faculty of Science \& Engineering, University of \\ Manchester, 131 Princess Street, M1 7DN, Manchester, United Kingdom \\ Phone: +44 161306 5173; fax: +44 (161) 275 1311; e-mail address: nicholas.turner@manchester.ac.uk
}

Received: ((will be filled in by the editorial staff))

Supporting information for this article is available on the WWW under http://dx.doi.org/10.1002/adsc.201\#\#\#\#\#.((Please delete if not appropriate))

\begin{abstract}
An enzymatic strategy for the preparation of $(R)-$ $\beta$-arylalanines employing phenylalanine aminomutase and ammonia lyase (PAM and PAL) enzymes has been demonstrated. Candidate PAMs with the desired $(S)$ selectivity from Streptomyces maritimus (EncP) and Bacillus sp. (PabH) were identified via sequence analysis using a well-studied template sequence. The newly discovered $\mathrm{PabH}$ could be linked to the first ever proposed biosynthesis of pyloricidin-like secondary metabolites and was shown to display better $\beta$-lyase activity in many cases. In spite of this, a method combining the higher conversion of EncP with a strict $\alpha$-lyase from Anabaena variabilis (AvPAL) was found to be more amenable, allowing kinetic resolution of five racemic substrates and a preparative-scale reaction with $>98 \%(R)$ enantiomeric excess. This work represents an improved and enantiocomplementary method to existing biocatalytic strategies, allowing simple product separation and modular telescopic combination with a preceding chemical step using an achiral aldehyde as starting material.
\end{abstract}

Keywords: $\beta$-amino acids; biocatalysis; enzyme cascades; aminomutases; ammonia lyases

\section{Introduction}

Phenylalanine aminomutase (PAM) enzymes, which catalyse the $\alpha$ - to $\beta$-isomerisation of the proteinogenic amino acid phenylalanine (Scheme 1), are seemingly rare in nature with only a handful of confirmed and predicted examples reported. The former include characterised enzymes from various species of yew tree, all involved in the production of the cytotoxic agent taxol ${ }^{[1]}$ and distant relatives associated with antibiotic synthesis in two distinct bacteria. ${ }^{[2-4]} \mathrm{A}$ PAM-like enzyme is also proposed to form part of the biosynthesis of the fungal toxin cyclochlorotine in Talaromyces islandisum based on identification of a candidate predicted open reading frame within the biosynthetic gene cluster. $^{[5]}$ The lack of characterisation with this class of enzyme is surprising given the detailed structural and biochemical knowledge of known enzymes ${ }^{[6-10]}$ and the wealth of organisms shown to produce $\beta$ phenylalanine-containing compounds. ${ }^{[2,11-14]}$ Progress in this area is likely hindered by the poor quality of enzyme sequence annotations in biological databases - a fact which itself precludes correct identification biosynthetic pathways for known and novel bioactive molecules applicable to medical research. This problem has already been highlighted within this particular enzyme family by efforts to uncover novel aminomutases specific to tyrosine (TAMs). ${ }^{[15]}$

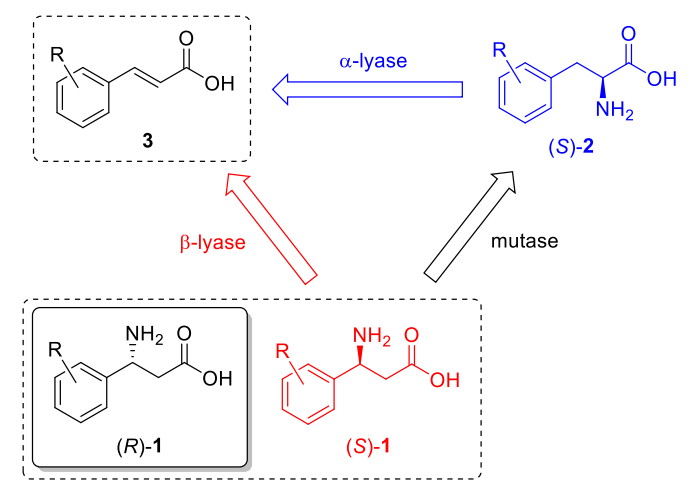

Scheme 1. Strategies for the kinetic resolution of $\beta$ phenylalanine derivatives via selective conversion of a single enantiomer to the corresponding acrylic acid.

Despite the small number of investigations of PAMs, these enzymes are of great interest in a biocatalytic context where their isomerisation activity has been used to access enantiopure $\beta$-arylalanines. This class of compounds are known chiral precursors in synthetic chemistry, where they are used to build small molecule pharmaceuticals ${ }^{[16,17]}$ as well as more complex peptide-mimicking therapeutics. ${ }^{[18-20]}$ 
Extensive studies have been done with both the $(S)$ selective AdmH from Pantoea agglomerans and $(R)$ selective TcPAM from Taxus canadensis starting with various unnatural and more readily-accessible $\alpha$ phenylalanine derivatives to produce either enantiomer of various $\beta$-phenylalanine analogues. ${ }^{[9,10]}$ Interestingly $\mathrm{AdmH}$ has been reported to produce small amounts of cinnamate during interconversion of phenylalanine regioisomers, indicating $\alpha$ - and / or $\beta$-lyase side activity. ${ }^{[3,10]}$ The absolute requirement for enantiopure starting material in these cases (due the strict enantiopreference of aminomutase enzymes) has also been addressed via combination of the $(R)$ PAM with a promiscuous alanine racemase from Pseudomonas putida, allowing racemic substrates to be converted to the desired product. ${ }^{[21]}$

Similarly the near-identical PAM orthologue from the Chinese subspecies of Taxus wallichiana has been used in the opposite direction to remove $(R)-\beta$ phenylalanine leaving the pure $(S)$-enantiomer. To shift the equilibrium towards full kinetic resolution and remove the unwanted $\alpha$-regioisomer, an ammonia lyase from Petroselinum crispum was employed in tandem. This approach is particularly attractive for preparative applications as the remaining enantiopure product can be simply separated from the cinnamic acid by-product via acidification and / or ion exchange. ${ }^{[22]}$ Despite this, there exists no PAMmediated method for preparing the opposite enantiomer via destruction of the $(S)$-form. An enantiocomplementary biocatalytic strategy does exist in which a $\beta$-amino acid transaminase is employed to convert the unwanted isomer to the corresponding $\beta$-keto acid. This method, however involves a co-substrate amine acceptor pyruvate thus producing the $\alpha$-amino acid alanine as a waste product. ${ }^{[23]}$ As amino acid mixtures are difficult to separate, a route which results in just the $(R)$ enantiomer and cinnamate would be a desirable addition to the current suite of biocatalytic strategies.
In light of previous research, the goal of this work was to expand the knowledge and application of $(S)$ PAMs beyond AdmH whilst also developing a kinetic resolution method complementary to those already in existence. To do this, we sought to find and investigate other enzymes in the family with potentially useful $(S)$-PAM and / or $\beta$-lyase activity to allow selective removal of a single enantiomer of various $\beta$-arylalanines $(S)$-1 to yield their counterpart cinnamic acids $\mathbf{3}$ with or without additional enzyme partners (Scheme 1).

\section{Results and Discussion}

As AdmH is the only enzyme whose $(S)$-selective aminomutase activity has been exploited in a biocatalytic context, other family members were picked out for investigation. This was done using the basic local alignment search tool (BLAST) to identify candidates from publically-available sequence data, using the AdmH primary sequence as a query. After sequence alignment, the hits were inspected for the function discriminating residues F455 (reported to confer an (S)-PAM-specific substrate binding trajectory in $\mathrm{AdmH})^{[6]}$ and Q456 which is known to differentiate histidine ammonia lyase (HAL) activity from all other family members. ${ }^{[15]}$ Any sequences with an E aligning with position 456 in $\mathrm{AdmH}$ were discarded as putative HALs, leaving 19 potential mutases, all displaying $\mathrm{F}$ at the position homologous to 455 . One of these was the phenylalanine ammonia lyase (PAL) EncP from Streptomyces maritimus - an enzyme known to possess (S)-PAM activity but that has never been used in biocatalytic isomerisation reactions. As all the other identified sequences were uncharacterised and annotated electronically as HALs, genetic context analyses were performed to add evidence to the simple functional assignment used in this study.

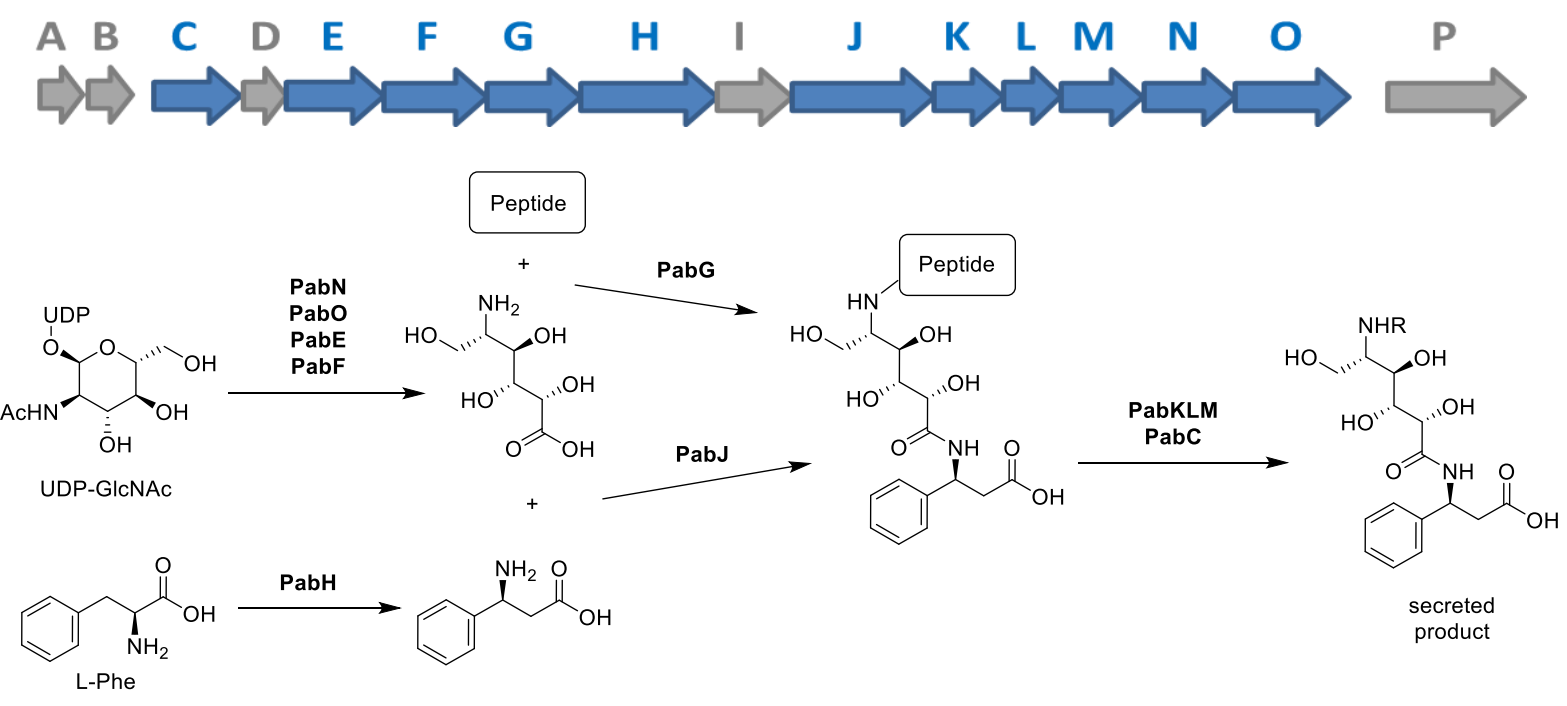

Figure 1. The proposed pyloricidin analogue biosynthesis $(\mathrm{pab})$ gene cluster and biosynthetic pathway for pyloricidin-like natural products from primary metabolites including phenylalanine (L-Phe) and uridine diphosphate $N$-acetylglucosamine (UDP-GlcNAc). 
The only natural products known to involve (S)-PAM activity in their metabolism are the polyketide (PK) stubomycin $^{[4]}$ and the non-ribosomal peptide (NRP) andrimid. ${ }^{[2]}$ As such, the situation of many of our uncovered genes within operons resembling PK/NRP synthesis clusters was promising, adding weight to predictions that they were all misannotated (SI). The case of one such arrangement, from Bacillus sp. strain LM 4-2, could even be linked via a retro-biosynthetic strategy to the secondary metabolism of a pyloricidinlike secondary metabolite (Figure 1). Even though the narrow spectrum pyloricidin class of antibiotics was isolated from species of Bacillus over a decade ago, ${ }^{[11,12]}$ its biosynthesis has since remained a mystery. Through inspection of the various open reading frames surrounding the 'PAM' locus in strain LM 4-2, genes for the conversion of primary metabolites into amino acid precursors, construction of the peptide and even processing and efflux of the final antibiotic could be identified (SI). This included a pathway from a nucleotide sugar to the unusual 5amino-2,3,4-trihydroxy-6-oxohexanoic acid - a precursor which, to our knowledge, is unique in characterised secondary metabolic peptides. Given this increased support of our initial assignment, the newly dubbed $\mathrm{PabH}$ was chosen along with EncP for investigation of their potential to resolve enantiomers of $\beta$-phenylalanine derivatives.

The synthetic gene encoding codon-optimised $\mathrm{PabH}$ was obtained and subcloned to a create a construct analogous to that used in previous investigations with EncP ${ }^{[24,25]}$ Both plasmids were used to obtain E. coli BL21(DE3) whole cell catalysts harbouring the relevant overproduced PAM. Biotransformations were performed with $5 \mathrm{mM} \mathrm{rac-1}$ and $50 \mathrm{mg}$ whole cells in $1 \mathrm{~mL}$. The reaction temperature was set to $30^{\circ} \mathrm{C}$ at $\mathrm{pH} 8.0$, as these are conditions where EncP is known to display mutase activity. ${ }^{[24]}$ After 24 hours the conversion of EncP was found to be superior to that of $\mathrm{PabH}$ in all cases, even achieving 50\% conversion with substrates $\mathbf{1 e}$ and $\mathbf{1 i}$ (Table 1). In all cases, however, the enzymes were found to act as both aminomutases and $\beta$-lyases to varying degrees, contaminating all mixtures with $\alpha$-amino acid $\mathbf{2}$. The most promising reaction in this respect was $\mathbf{1 h}$ with $\mathrm{PabH}$, giving about half the conversion desired but a mutase:lyase ratio of 12:88 - far lower than any such ratio with EncP. In spite of this, attempts to improve conversion and product ratios, such as additional reaction time, cell loading and elevated temperature/pH showed no improvement (see SI). As such the cascade strategy was attempted with EncP by employing an $\alpha$-lyase from Anabaena variabilis (AvPAL) $^{[26]}$ to remove the contaminant 2 and displace the equilibrium of the mutase reaction toward complete consumption of $(S)-\mathbf{1}$.
Table 1. Comparison of the aminomutase and $\beta$-lyase propensities of $\mathrm{PabH}$ and EncP on racemic $\beta$-phenylalanine derivatives $(r a c-1)$.

\begin{tabular}{|c|c|c|c|c|c|}
\hline & & & (S)-2a-m & & \\
\hline \multirow[b]{2}{*}{ Subs. } & \multirow[b]{2}{*}{$\mathbf{R}$} & \multicolumn{2}{|c|}{ PabH } & \multicolumn{2}{|c|}{ EncP } \\
\hline & & $\begin{array}{l}\text { Conv. } \\
{[\%]^{[a]}}\end{array}$ & $\begin{array}{l}\text { Ratio } \\
2: 3^{[a]}\end{array}$ & $\begin{array}{l}\text { Conv. } \\
{[\%]^{[\mathrm{a}]}}\end{array}$ & $\begin{array}{l}\text { Ratio } \\
2: 3^{[a]}\end{array}$ \\
\hline $1 \mathbf{a}$ & $\mathrm{H}$ & 11 & $79: 21$ & 39 & $46: 54$ \\
\hline $1 b$ & $2-\mathrm{F}$ & 14 & $92: 8$ & 46 & $77: 23$ \\
\hline 1c & $3-\mathrm{F}$ & 12 & $92: 8$ & 39 & $64: 36$ \\
\hline 1d & $4-\mathrm{F}$ & 6 & $58: 42$ & 37 & $52: 48$ \\
\hline 1e & $2-\mathrm{Cl}$ & 20 & $90: 10$ & 55 & $81: 19$ \\
\hline 1f & $4-\mathrm{Cl}$ & 5 & $73: 27$ & 30 & $91: 9$ \\
\hline $1 g$ & $3-\mathrm{Br}$ & 23 & $12: 88$ & 46 & $57: 43$ \\
\hline 1h & $4-\mathrm{Br}$ & 12 & $12: 88$ & 38 & $69: 31$ \\
\hline $1 \mathbf{i}$ & $2-\mathrm{NO}_{2}$ & 15 & $47: 53$ & 55 & $73: 27$ \\
\hline $\mathbf{1 j}$ & $3-\mathrm{NO}_{2}$ & 1 & $>99: 1$ & 37 & $98: 2$ \\
\hline $1 k$ & 4-MeO & 3 & $12: 88$ & 23 & $46: 54$ \\
\hline 11 & 2-Me & 8 & $23: 77$ & 42 & $62: 28$ \\
\hline $1 \mathrm{~m}$ & 3-Me & 2 & 39:61 & 27 & $63: 37$ \\
\hline
\end{tabular}

Expt. cond.: $5 \mathrm{mM}$ 1a-m, $50 \mathrm{mg} \mathrm{mL}^{-1}$ wet cell weight, 100 $\mathrm{mM}$ borate buffer, $\mathrm{pH} 8.0,30^{\circ} \mathrm{C}, 24 \mathrm{~h} .{ }^{[\mathrm{a}}$ Conversion and product ratios determined by HPLC on a non-chiral phase.

Addition of $25 \mathrm{mg}$ lyophilised AvPAL whole cells to the reaction formula was shown to increase conversion in most cases, with only 4 of the 13 substrates giving below $40 \%$ conversion and the best 5 biotransformations suggesting quantitative conversion (Table 2). The purity of the amino acid component of each reaction was also found to be greatly improved, with $\beta: \alpha$ ratios all above 90:10. As an investigation of the scalability of the reaction the best biotransformation, which indicated complete consumption of the $(S)$-enantiomer and only a trace of $\alpha$-amino acid, was repeated with $10 \mathrm{mM}$ 1c. Although conversion was unaltered there was evidence of accumulation of amino acid 2c, indicating that the lyase activity of the enzyme combination was insufficient to remove this side product fully (Table 3). 
Table 2. Kinetic resolution of racemic $\beta$-phenylalanine derivatives $(r a c-1)$ via an EncP-AvPAL cascade.

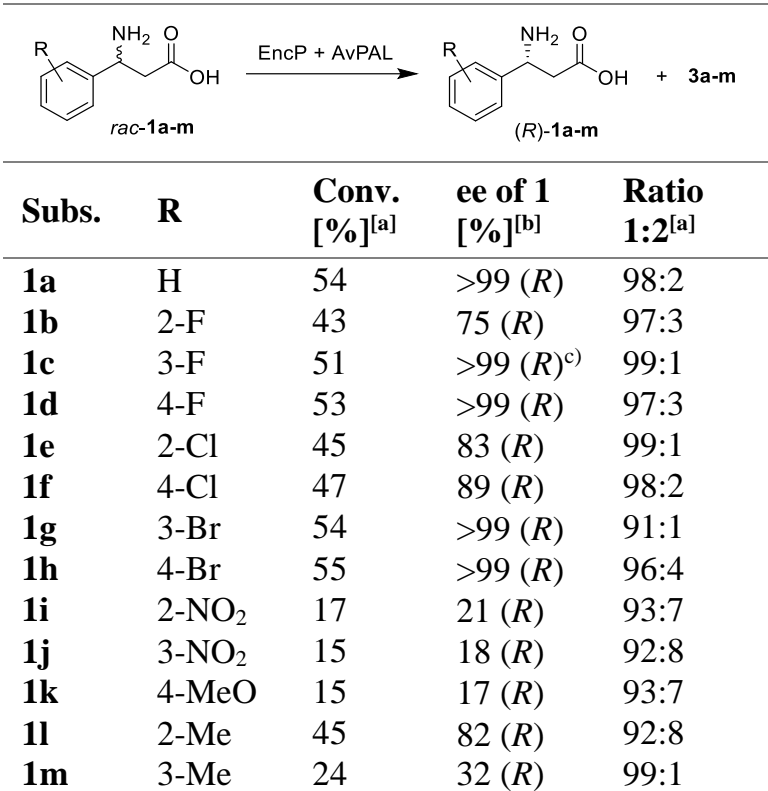

Expt. cond.: $5 \mathrm{mM}$ 1a-m, $50 \mathrm{mg} \mathrm{mL} \mathrm{m}^{-1}$ EncP wet cell weight, $25 \mathrm{mg} \mathrm{mL}^{-1}$ AvPAL dry cell weight, $100 \mathrm{mM}$ borate buffer, $\mathrm{pH} 8.0,30^{\circ} \mathrm{C}, 24 \mathrm{~h}$. a) Conversion and product ratios determined by HPLC on a non-chiral phase. b) Enantiomeric excesses calculated theoretically from conversion assuming strict $(S)$-selectivity of EncP. c) Enantiomeric excess confirmed via HPLC on a chiral phase.

Table 3. Effect of $\mathrm{pH}$ on the kinetic resolution of racemic $\beta$-phenylalanine (rac-1a) by AvPAL and EncP.

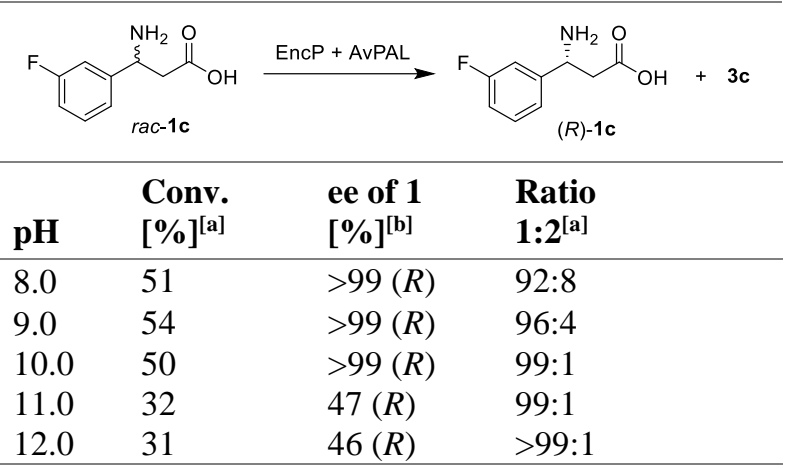

Expt. cond.: $5 \mathrm{mM} \mathrm{1c}, 50 \mathrm{mg} \mathrm{mL} \mathrm{mL}^{-1} \mathrm{EncP}$ wet cell weight, $25 \mathrm{mg} \mathrm{mL}^{-1}$ AvPAL dry cell weight, $100 \mathrm{mM}$ borate buffer, $\mathrm{pH} 8.0-12.0,30^{\circ} \mathrm{C}, 24 \mathrm{~h} .{ }^{[a]}$ Conversion and product ratios determined by HPLC on a non-chiral phase. [b] Enantiomeric excesses calculated theoretically from conversion assuming strict $(S)$-selectivity of EncP.

To ascertain whether the decrease in amino acid purity was due to the suboptimal conditions with regard to AvPAL activity, ${ }^{[26]}$ a $\mathrm{pH}$ profile was conducted. This revealed an increase in apparent lyase activity accompanied by a decrease in mutase activity within the system with increasing $\mathrm{pH}$ (Table 4). The two reactions were seemingly balanced at an intermediate $\mathrm{pH}$ of 10 where the $\beta: \alpha$ ratio was better than at lower values, but overall conversion was not affected detrimentally by excessively alkaline conditions. Having established a more optimal $\mathrm{pH}$ buffer composition for the cascade, the intensification of the reaction was continued via sequential biotransformations with increasing substrate concentration (Table 4). Although conversion values continued to indicate full kinetic resolution had been reached in all experiments, chiral analysis of the reaction mix revealed that at $100 \mathrm{mM}$ traces of the unwanted $(S)$-1c could be detected. As such no higher concentrations were tested. In spite of this, the enantiomeric excess values calculated even for this incomplete reaction were found to be $98 \%(R)$.

Table 4. Effect of varying substrate concentration on the kinetic resolution of $r a c-1 c$ by AvPAL and EncP.

\begin{tabular}{|c|c|c|c|}
\hline $\begin{array}{l}\text { Substrate conc. } \\
{[\mathrm{mM}]}\end{array}$ & $\begin{array}{l}\text { Conv. } \\
{[\%]^{[a]}}\end{array}$ & $\begin{array}{l}\text { ee of 1c } \\
{[\%]^{[b]}}\end{array}$ & $\begin{array}{l}\text { Ratio } \\
1 c: 2 c^{[a]}\end{array}$ \\
\hline 10 & 51 & $>99(R)$ & $99: 1$ \\
\hline 20 & 50 & $>99(R)$ & 99:1 \\
\hline 35 & 50 & $>99(R)$ & $99: 1$ \\
\hline 50 & 51 & $>99(R)$ & 99:1 \\
\hline 60 & 50 & $>99(R)$ & $97: 3$ \\
\hline 75 & 50 & $>99(R)$ & $98: 2$ \\
\hline 100 & 49 & $98(R)$ & $98: 2$ \\
\hline
\end{tabular}

Expt. cond.: 10-100 mM 1a-m, $50 \mathrm{mg} \mathrm{mL}^{-1}$ EncP wet cell weight, $25 \mathrm{mg} \mathrm{mL}^{-1}$ AvPAL dry cell weight, $100 \mathrm{mM}$ borate buffer, $\mathrm{pH} 10.0,30^{\circ} \mathrm{C}, 24 \mathrm{~h}$. ${ }^{\text {a] }}$ Conversion and product ratios determined by HPLC on a non-chiral phase. ${ }^{[b]}$ Enantiomeric excesses determined via HPLC on a chiral phase.

Having demonstrated promising intensification of the kinetic resolution strategy, a preparative scale synthesis was attempted with $100 \mathrm{mg} \mathrm{rac}-\mathbf{1 c}, 300 \mathrm{mg}$ EncP wet whole cells and $150 \mathrm{mg}$ AvPAL lyophilisate in $6 \mathrm{~mL} \mathrm{pH} 10$ borate buffer. Following isolation after a 24 hour incubation at $30^{\circ} \mathrm{C}, 40.5 \mathrm{mg}$ product was obtained and shown to be $>95 \%$ pure with an ee $>98 \%(R)$ by HPLC. This represents a 25 fold improvement in space time yield over the previously reported, enantiocomplementary PAMPAL cascade, requiring one third the reaction time, just a fifth of the volume and giving an additional $16.5 \mathrm{mg}$ of isolated product. ${ }^{[22]}$

Furthermore, we sought to investigate the in situ chemo-enzymatic combination of substrate synthesis and kinetic resolution, with the advantage of starting from the inexpensive and commercially available benzaldehydes. However, since the synthesis of $\beta$ amino acids requires higher temperatures and an organic solvent (typically refluxing EtOH), ${ }^{[27]}$ a telescopic approach was required to overcome the issue of incompatible conditions for the two steps (Scheme 2). Using again the preparation of $(R)-\mathbf{1 c}$ as a model reaction, rac-1c was prepared from $m$ fluorobenzaldehyde 4, malonic acid and an 
ammonium salt in ethanol, then the crude mixture was diluted with the biotransformation buffer (to $6 \mathrm{mM}$ final concentration of $\mathrm{rac}-\mathbf{1 c}$ ), cells were added and the mixture incubated at $30^{\circ} \mathrm{C}$ until complete resolution. This approach was shown to afford $(R)-\mathbf{1 c}$ with an enantiomeric excess of $99 \%$ from $\mathbf{4}$, demonstrating the efficient combination of the two steps in a one-pot telescopic fashion, with no need for isolation of the intermediate rac-1c (as already demonstrated previously with the one-pot telescopic synthesis of $\alpha$-amino acids by coupling of cinnamic acids synthesis and PAL-mediated amination ${ }^{[28,29]}$ ).

It is worth noting that the synthesis of rac-1c from $\mathbf{4}$ produces considerable amounts of the corresponding cinnamic acid 3c as a by-product, and to minimise this side-reaction different ammonium sources and different temperatures were tested (the best conditions were found to be 2 equiv. of ammonium formate, $60^{\circ} \mathrm{C}, 6 \mathrm{~h}$ ), giving a ratio of $87: 13$ of $\mathrm{rac}-\mathbf{1 c}: 3 \mathrm{c}$. With complete kinetic resolution of this mixture upon dilution in the EncP-AvPAL tandem biotransformation, a yield of $43.5 \%$ (of a possible $50 \%$ ) can be achieved. Therefore, our formal asymmetric synthesis (over the two steps) is a particularly elegant combination as the by-product of the chemical and initial enzymatic transformations are identical to the product of the final biocatalyst. In this way, no further complexity is introduced to the general work up procedure required to isolate the enantiopure $\beta$-amino acid.

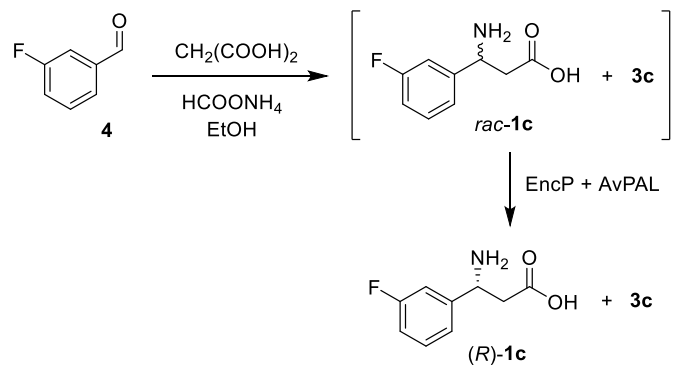

Scheme 2. Asymmetric synthesis of $(R)-1 \mathrm{c}$ from the corresponding benzaldehyde $\mathbf{4}$, via a one-pot telescopic chemo-enzymatic cascade with $\mathbf{3 c}$ as the only by-product.

\section{Conclusion}

In summary, we have reported the investigation of two enzymes with respect to their previously unexploited $(S)$-selective aminomutase/ $\beta$-lyase activity, as applied to the kinetic resolution of racemic $\beta$-arylalanines. The biocatalysts chosen for comparison were EncP, a known ammonia lyase with unexplored (S)-PAM side activity, and $\mathrm{PabH}$, an enzyme discovered, linked to antibiotic synthesis and characterised for the first time in this work. An initial comparison of the two candidates revealed $\mathrm{PabH}$ to be a better $\beta$-lyase than EncP making it a more promising candidate for single biocatalyst kinetic resolution methods. However lower activity and unsuccessful optimisation attempts led to the use of
EncP instead as part of a two enzyme cascade. This system was shown to be applicable across a of range amino acid starting materials, tunable in terms of amino acid product ratios and scalable up to $100 \mathrm{mM}$ substrate concentration and $100 \mathrm{mg}$ substrate loading with excellent resolution in most cases. This highly selective method represents an improved and complementary route to previously reported PAMPAL combinations and can be easily integrated with a chemical step in a one-pot fashion to produce enantiopure $\beta$-amino acid product from a simple achiral starting material. In addition to the biotransformation strategies reported, the method used to mine sequence databases in his study could be taken further to uncover more of nature's elusive $(S)$ PAMs, potentially with improved biocatalytic properties and associated with additional, as of yet undiscovered biosynthetic pathways for bioactive secondary metabolites.

\section{Experimental Section}

Bacterial transformations. Plasmids containing codonoptimised genes encoding EncP and AvPAL were used as previously described. The codon-optimised gene encoding $\mathrm{PabH}$ was ordered from Thermo Fisher Scientific with the inclusion of an upstream NdeI and downstream XhoI endonuclease restriction site. The gene was then subcloned into a pET-28a expression vector following a procedure used previously to form the pET-28a-EncP construct. ${ }^{[24]}$ All three plasmids were then used as previously described to transform Escherichia coli BL21(DE3) in accordance with the manufacturer's protocol, producing single colonies on LB-agar microbiological plates supplemented with the appropriate antibiotic (kanamycin for EncP and $\mathrm{PabH}$, ampicillin for AvPAL).

Preparation of whole cell biocatalysts. LB medium (5 $\mathrm{mL}$, supplemented with the appropriate antibiotic) was inoculated with a single colony of $E$. coli BL21(DE3) containing the suitable plasmid and grown for $16 \mathrm{~h}$ at $37^{\circ} \mathrm{C}$ and $250 \mathrm{rpm}$. This starter culture was then used to inoculate LB-based autoinduction medium ${ }^{[30]} \quad(800 \quad \mathrm{~mL}$, supplemented with the appropriate antibiotic), which was incubated at $18^{\circ} \mathrm{C}$ and $250 \mathrm{rpm}$ for 4 days. The cells were pelleted by centrifugation (4000 rpm, $12 \mathrm{~min})$ and separated from the supernatant for storage of the wet cell mass at $-20^{\circ} \mathrm{C}$ until further use. In the case of AvPAL, a lyophilised dry cell powder formulation was used as reported previously. ${ }^{[29]}$

General biotransformation procedure. All reactions were carried out using the E. coli BL21(DE3) whole cell formulations containing the enzyme of choice at the appropriate concentration, resuspended in a solution of 1a$\mathbf{m}$ in borate buffer. The mixture was incubated at $30^{\circ} \mathrm{C}$, unless otherwise stated, and $250 \mathrm{rpm}$ for $24 \mathrm{~h}$. Postincubation, biotransformation samples were mixed with an equal volume of $\mathrm{MeOH}$, vortexed, and centrifuged (13000 $\mathrm{rpm}, 3 \mathrm{~min}$ ) to remove the whole cell biocatalyst. The supernatant containing reactants and products was 
transferred to a $0.45 \mu \mathrm{m}$ filter vial and used directly for HPLC analysis (see Supporting Information for conditions).

Chemical synthesis of rac-1c from 4 for the telescopic synthesis-resolution sequence. To a solution of $\mathrm{m}$ fluorobenzaldehyde 4 (1.24 g, $10 \mathrm{mmol}, 1.0$ equiv.) in EtOH $(20 \mathrm{~mL})$, were added malonic acid $(1.30 \mathrm{~g}, 12.5$ mmol, 1.25 equiv.) and ammonium formate $(1.26 \mathrm{~g}, 20$ mmol, 2.0 equiv.). The mixture was heated for $4 \mathrm{~h}$ under reflux (sand bath $100^{\circ} \mathrm{C}$ ), during which time the $\beta$-amino acid product 1c partly precipitated out. The mixture was then cooled to room temperature, giving a thick white suspension containing $10 \mathrm{mmol} \mathrm{rac}$-1c in $20 \mathrm{~mL}$ (approx. $500 \mathrm{mM}$ ). The mixture was shaken vigorously to resuspend the solid, an aliquot $(0.05 \mathrm{~mL})$ was withdrawn and diluted with borate buffer $(0.45 \mathrm{~mL}, 100 \mathrm{mM}, \mathrm{pH} 8.0)$ for the biotransformation, performed as described in the previous section.

\section{Acknowledgements}

This work was funded by the European Union's $7^{\text {th }}$ Framework program FP7/2007-2013 under grant agreement no. 289646 (KYROBIO). S. T. A. and F. P. were supported by the Biotechnology and Biological Sciences Research Council (BBSRC) and Glaxo-SmithKline (GSK) under the Strategic Longer and Larger (sLoLa) grant initiative ref. BB/K00199X/1. We thank the Royal Society for a Wolfson Research Merit Award (N.J.T.)

\section{References}

[1] C. L. Steele, Y. Chen, B. A. Dougherty, W. Li, S. Hofstead, K. S. Lam, Z. Xing and S. J. Chiang, Arch. Biochem. Biophys., 2005, 438, 1-10.

[2] M. Jin, M. A. Fischbach and J. Clardy, J. Am. Chem. Soc., 2006, 128, 10660-10661.

[3] N. A. Magarvey, P. D. Fortin, P. M. Thomas, N. L. Kelleher and C. T. Walsh, ACS Chem. Biol., 2008, 3, 542-554.

[4] F. Kudo, K. Kawamura, A. Uchino, A. Miyanaga, M. Numakura, R. Takayanagi and T. Eguchi, Chembiochem, 2015, 16, 909-14.

[5] T. Schafhauser, N. Kirchner, A. Kulik, M. M. E. Huijbers, L. Flor, T. Caradec, D. P. Fewer, H. Gross, P. Jacques, L. Jahn, J. Jokela, V. Leclère, J. LudwigMüller, K. Sivonen, W. J. H. van Berkel, T. Weber, W. Wohlleben and K.-H. van Pée, Environ. Microbiol., 2016, In Press.

[6] S. Strom, U. Wanninayake, N. D. Ratnayake, K. D. Walker and J. H. Geiger, Angew. Chem. Int. Ed. Engl., 2012, 51, 2898-902.

[7] N. D. Ratnayake, U. Wanninayake, J. H. Geiger and K. D. Walker, J. Am. Chem. Soc., 2011, 133, 8531-8533.

[8]L. Feng, U. Wanninayake, S. Strom, J. Geiger and K. D. Walker, Biochemistry, 2011, 50, 2919-2930.

[9] U. Wanninayake, Y. Deporre, M. Ondari and K. D. Walker, Biochemistry, 2011, 50, 10082-90.

[10] N. D. Ratnayake, N. Liu, L. A. Kuhn and K. D. Walker, ACS Catal., 2014, 4, 3077-3090.
[11] Y. Nagano, K. Ikedo, M. Izawa, S. Tsubotani, O Nishimuraband and M. Fujinoc, J. Antibiot. (Tokyo), 2001, 54, 934-947.

[12] M. Nakaoa, K.-I. Miyagawa, Y. Nakano, T. Sakane, M. Tada, O. Nishimura and M. Fujino, J. Antibiot. (Tokyo)., 2001, 54, 926-933.

[13] H. Morita, S. Nagashima, K. Takeya, H. Itokawa and Y. Iitaka, Tetrahedron, 1995, 51, 1121-1132.

[14] A. C. Ghosh, A. Manmade, J. M. Townsend, A Bousquet, J. F. Howes and A. L. Demain, Appl. Environ. Microbiol., 1978, 35, 1074-1078.

[15] D. Krug and R. Müller, Chembiochem, 2009, 10, $741-50$.

[16] X. Huang, E. O. Brien, F. Thai and G. Cooper, Org. Process Res. Dev., 2010, 14, 592-599.

[17] S. Ruf, C. Buning, H. Schreuder, G. Horstick, W. Linz, T. Olpp, J. Pernerstorfer, K. Hiss, K. Kroll, A. Kannt, M. Kohlmann, D. Linz, T. Hübschle, H. Rütten, K. Wirth, T. Schmidt and T. Sadowski, J. Med. Chem., 2012, 55, 7636-49.

[18] M.-I. Aguilar, A. W. Purcell, R. Devi, R. Lew, J. Rossjohn, A. I. Smith and P. Perlmutter, Org. Biomol. Chem., 2007, 5, 2884-2890.

[19] D. L. Steer, R. A. Lew, P. Perlmutter, A. I. Smith and M.-I. Aguilar, Curr. Med. Chem., 2002, 9, 811-822.

[20] K. Gademann, T. Hintermann and J. V Schreiber, Curr. Med. Chem., 1999, 6, 905-925.

[21] B. M. Cox, J. B. Bilsborrow and K. D. Walker, J. Org. Chem., 2009, 74, 6953-6959.

[22] B. Wu, W. Szymański, S. de Wildeman, G. J. Poelarends, B. L. Feringa and D. B. Janssen, Adv. Synth. Catal., 2010, 352, 1409-1412.

[23] H.-S. Bea, H.-J. Park, S.-H. Lee and H. Yun, Chem. Commun. (Camb)., 2011, 47, 5894-6.

[24] C. Chesters, M. Wilding, M. Goodall and J. Micklefield, Angew. Chem. Int. Ed. Engl., 2012, 51, 4344-8.

[25] N. J. Weise, F. Parmeggiani, S. T. Ahmed and N. J. Turner, J. Am. Chem. Soc., 2015, 137, 12977-12983.

[26] M. C. Moffitt, G. V Louie, M. E. Bowman, J. Pence, P. Joseph and B. S. Moore, Biochemistry, 2008, 46, 1004-1012.

[27] C. Y. K. Tan and D. F. Weaver, Tetrahedron, 2002, 58, 7449-7461.

[28] F. Parmeggiani, S. T. Ahmed, N. J. Weise and N. J. Turner, Tetrahedron, 2015, in press

[29] N. J. Weise, S. T. Ahmed, F. Parmeggiani, E. Siirola, A. Pushpanath, U. Schell and N. J. Turner, Catal. Sci. Technol., 2016, 6, 4086-4089.

[30] F. W. Studier, Protein Expr. Purif., 2005, 41, $207-$ 234. 


\section{UPDATE}

Kinetic Resolution of Aromatic $\beta$-Amino Acids Using a Combination of Phenylalanine Ammonia Lyase and Aminomutase Biocatalysts

Adv. Synth. Catal. Year, Volume, Page - Page

Nicholas J. Weise, Syed T. Ahmed, Fabio

Parmeggiani and Nicholas J. Turner*

phenylalanine aminomutase phenylalanineammonialyase from Streptomyces maritimus from Anabaena variabilis
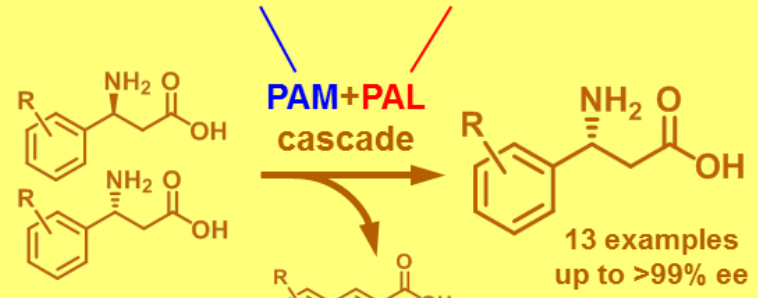